\title{
Effects of Fluoridated and Non- Fluoridated Bleaching Agents on Bovine Surface Enamel
}

\author{
Prashant Babaji $^{1 *}$, Pooja Bhagwat ${ }^{2}$, Mahesh Melkundi ${ }^{2}$ and Vanitha Mehta ${ }^{3}$ \\ ${ }^{1}$ Department of Pedodontics, India \\ ${ }^{2}$ Department of Oral Pathology, India \\ ${ }^{3}$ Department of Pedodontics, Rajasthan, India \\ *Corresponding author: Prashant Babaji, Department of Pedodontics, Karnataka, India
}

Received: 㭗 November 29, 2018

Published: 㘹December 17, 2018

\section{Introduction}

In the modern era, aesthetic dentistry is becoming famous. The demand of tooth bleaching is increasing day by day and it has become the treatment of choice for tooth discoloration. If there is deposition of chromatogenic material into dentin and enamel during the tooth development stage or after eruption, it leads to intrinsic tooth discoloration [1]. Among various bleaching techniques for intrinsic tooth discoloration, vital and non-vital bleaching techniques are common one. They use oxidizing agents such as hydrogen peroxide to remove intrinsic stains. They are widely used agents as they have safe to use. These properties have made them popular. Further modifications in these agents have opened multiple options for dentists in managing tooth discoloration [2]. Carbamide peroxide (CP) is a perhydrol-urea and hydrogen peroxide carbamide compound which degrades to urea and hydrogen peroxide. This agent with "night guard" bleaching technique, have proved effective and efficient in providing good results. However, altered surface morphology, decreased microhardness and loss of dental hard tissue volume are among few side effects of bleaching as shown by various authors. $10 \%$ CP has been proved to decrease the enamel microhardness as compared to higher level [3]. However, a study performed by Potocnik et al. [4] found that $10 \%$ CP causes local microstructural changes and there is no affect on enamel microhardness. $10 \% \mathrm{CP}$ is a safest bleaching agent as demineralization is not clinical evident, moreover, it is soon followed by remineralization. Fluoridated bleaching agents are considered to reduce the adverse effects of tooth whitening. Topical fluoride is used to increase the hardness and acid resistance of demineralized teeth. It may be used in tooth sensitivity peripherally by occluding the dentinal tubules and reducing dentinal fluid flow. Hence, fluoride application may be used for treating post-bleaching sensitivity [5]. The present study was conducted to assess the effects of bleaching agents with and without fluoride as well as the post-bleaching fluoridation on bovine surface enamel.

\section{Materials \& Methods}

The present study was conducted in the department of Endodontics in year 2015. It included 60 non-carious anterior teeth specimens. The specimens were stored in buffered saline. These teeth were cut into halves using a slow speed rotary saw under water irrigation. After cutting teeth, specimens were embedded in epoxy resin with the labial surface parallel to the horizontal plane. The enamel surfaces were then ground with 320-grit silicon carbide abrasive paper using a mechanical grinder to create a flat surface of approximately $5 \mathrm{~mm}$. The specimens were then smoothed with 600- and 1000-grit silicon carbide abrasive paper and polished with a series of 30, 9, 6 and $1 \mathrm{~mm}$ diamond suspension. The specimens were then divided into five treatment groups:

a) Group I: It consisted of 12 control specimens soaked in Hank buffer saline solution (HBSS) at 37 degree C for 2 weeks.

b) Group II: It consisted of 12 specimens treated with $10 \%$ opalescence fluoride-free bleaching agent.

c) Group III: It consisted of 12 specimens treated with $10 \%$ opalescence fluoride-free bleaching agent with additional $2 \%$ neutral sodium fluoride gel for $3 \mathrm{~min}$.

d) Group IV: It consisted of 12 specimens treated with $10 \%$ opalescence PF bleaching agent with $0.11 \%$ fluoride.

e) Group V: It consisted of 12 specimens treated with an experimental bleaching agent Ex-037 containing 0.37\% fluoride. 
The specimens of group II, III, IV and V were bleached $8 \mathrm{~h} /$ day $\mathrm{X} 14$ days. The bleaching agents were applied on the enamel and stored at $100 \%$ humidity at 37 degree C. Rinsing with tap water was done after application of bleaching agent to each specimen for 1 minute and was stored in HBSS at 37 degree C. The color change, microhardness and surface topography were evaluated after 14 days. The color of each specimen was measured as baseline data on Day 0. The color of each specimen was assessed by the CIELab system in $\mathrm{L}$ a b mode using a dental colorimeter. The assessed area was the cervical area, $1 \mathrm{~mm}$ occlusal to the cemento-enamel junction. After the bleaching treatment, the specimens were

\section{Results}

Table 1: Mean of value of color difference in groups recorded at day 7 and 14 .

\begin{tabular}{|c|c|c|c|c|c|c|c|c|}
\hline \multirow{2}{*}{ Groups } & \multicolumn{4}{|c}{ Day 7 } & \multicolumn{3}{c|}{ Day 14 } \\
\cline { 2 - 9 } & L & a & b & E & L & a & b & E \\
\hline Group I & $1.6 \pm 0.72$ & $0.12 \pm 0.3$ & $0.32 \pm 0.38$ & $2.12 \pm 1.3$ & $2.6 \pm 0.52$ & $0.42 \pm 0.3$ & $0.12 \pm 1.18$ & $2.62 \pm 1.3$ \\
\hline Group II & $4.2 \pm 3.2$ & $0.14 \pm 0.3$ & $-0.14 \pm 0.2$ & $5.12 \pm 2.3$ & $7.2 \pm 2.25$ & $0.01 \pm 0.3$ & $-0.34 \pm 0.8$ & $7.8 \pm 2.6$ \\
\hline Group III & $3.02 \pm 3.4$ & $-0.32 \pm 0.31$ & $-0.15 \pm 0.2$ & $5.02 \pm 2.4$ & $5.02 \pm 3.4$ & $0.5 \pm 2.31$ & $-3.15 \pm 2.2$ & $7.12 \pm 1.4$ \\
\hline Group IV & $5.11 \pm 2.5$ & $-0.62 \pm 0.5$ & $-0.3 \pm 0.31$ & $6.32 \pm 2.1$ & $6.81 \pm 2.5$ & $0.12 \pm 0.6$ & $-3.3 \pm 01.9$ & $7.32 \pm 3.8$ \\
\hline Group V & $5.21 \pm 1.2$ & $-0.42 \pm 0.6$ & $-0.03 \pm 0.2$ & $6.82 \pm 2.6$ & $6.21 \pm 1.2$ & $0.42 \pm 0.7$ & $-4.04 \pm 0.2$ & $8.83 \pm 2.2$ \\
\hline
\end{tabular}

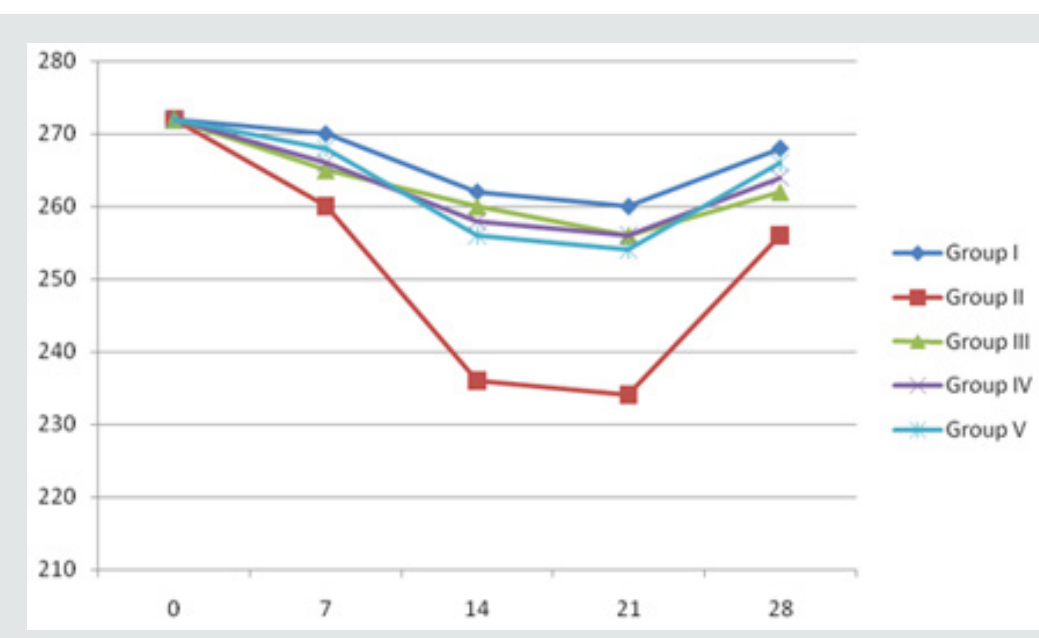

Graph 1: Microhardness in all groups.

Table I shows color change values differences in $\mathrm{L}$, a and $\mathrm{b}$ between Days 7, 14 and baseline. The lightness change in DL was more significant than in Da and Db on Day 7. In group I, there was no color change. Group II, III and IV showed DL and overall color change DE and increased by 3, 4 and 5 units, respectively (Table 1). Group II, III and IV showed comparable DL and DE values and greater than group I $(\mathrm{P}<0.01)$ on Day 14. Group I showed minimal whitening effect and values were $<3$ units. The color change was increased in DL and decreased in Db but unchanged in Da in groups II, III and IV. The DE in all groups exceeded by 7. There were significant changes in the DL, Da, Db values in four bleaching groups from Days 7 to 14. Graph I show microhardness in each group. At baseline (Day 0), microhardness in each group was $270 \mathrm{KHN}$. At day 7 it decreased in all groups (Graph 1). It was lowest in group II as compared to others group. The difference was significant $(\mathrm{P}<0.05)$. It further again inspected on Days 7 and 14 to measure the color changes. "L" represents the degree of gray and corresponds to a value of brightness. The "a" is a parameter in the red-green spectrum and "b" is a parameter in the blue-yellow spectrum. The microhardness of the specimens used for color measurement was determined with a microhardness tester. Knoop hardness (KHN) was measured with a Knoop indenter three times at a load of $50 \mathrm{~g}$ for $5 \mathrm{~s}$. Specimens from all groups were examined for the surface morphology change on Day 14. All specimens were thoroughly cleaned and air-dried in a desiccator for $24 \mathrm{~h}$. Following the desiccating procedure, the specimens were gold sputtered then observed under a SEM. 
teeth. Thus, bovine teeth were used in present study. For the evaluation of bleaching methods, young bovine teeth are considered despite of higher lightness with the shade of bovine enamel than in human enamel. The present study was conducted to assess the effects of bleaching agents with and without fluoride as well as the post-bleaching fluoridation on bovine surface enamel. Fluoride helps in remineralizing dental erosion by forming a calcium fluoride layer and increasing resistance to acid attacks thus inhibiting demineralization. A recent study conducted by Attin et al. [6] assessed the remineralizing property of various fluoride applications following bleaching treatment. Fluoride application preserves hardness after bleaching. De Oliveira et al. [7] in their study commented that fluoride dentifrice along with bleaching treatment retains the enamel microhardness at baseline values. In present study we included 60 non carious anterior teeth specimen which were divided into five groups of 12 teeth each. In each group, bleaching treatment was performed. First, we evaluated the color change values in each group at day 7, 14, 21and 28. In group I, there was no color change whereas group II, III and IV showed color change increased by 3,4 and 5 units, respectively. There were significant changes in the $\mathrm{DL}, \mathrm{Da}, \mathrm{Db}$ values in four bleaching groups from Days 7 to 14. This agrees with Attin T et al. [6] we evaluated microhardness in each group. We found that group II had lowest microhardness as compared to other groups. However, at day 28, it started improving in all groups. Similar results were seen in study by Betke et al. [8] Adverse interactions between $\mathrm{CP}$ and fluoride may be resulted by adding fluoride in bleaching agent whereas calcium fluoride layer may hamper the whitening efficiency of CP. Wiegand et al. [9], in their study concluded that fluoridated bleaching gel has whitening efficiency comparable to that of other nonfluoridated agents. Burgmaier et al. [10] in their study revealed that bovine teeth treated with CP followed by highdosed fluoridation increased the fluoride uptake even though the structurally bound fluoride was lower than that in teeth receiving fluoridation only. In our study, we compared surface morphology in all groups. Group I showed unchanged enamel surface on the unbleached specimen. Group II and III showed significant alteration with erosion appearance. Group IV and V showed less distinct surface morphologic changes. They demonstrated minor dissolution of the prism core and peripheries [11].

\section{Conclusion}

In all groups, whitening efficiency was similar with increase in whiteness and decrease in yellow color saturation. Fluoridated bleaching gel improves whitening efficiency and results in less demineralization changes such as the erosion morphology and hardness loss.

\section{References}

1. Tanizawa Y (2005) Reaction characteristics of a tooth-bleaching agent containing $\mathrm{H}_{2} \mathrm{O}_{2}$ and $\mathrm{NaF}$ : in vitro study of crystal structure change in treated hydroxyapatite and chemical states of incorporated fluorine. J Cosmetic Scie 27(5): 295-296.

2. Gokay O, Tuncbilek M, Ertan R (2000) Penetration of the pulp chamber by carbamide peroxide bleaching agents on teeth restored with a composite resin. J Oral Rehab 27(5): 428-431.

3. Haywood VB, Heymann HO (1991) Nightguard vital bleaching: how safe is it? Quint Int 22(7): 515-523.

4. Potocnik I, Kosec L, Gaspersic D (2000) Effect of $10 \%$ carbamide peroxide bleaching gel on enamel microhardness, microstructure, and mineral content. J Endod 26(4): 203-206.

5. Sulieman M, Addy M, Macdonald E, Rees JS (2005) The bleaching depth of a $35 \%$ hydrogen peroxide based in-office product: a study in vitro. J Dent 33(1): 33-40.

6. Attin T, Kielbassa AM, Schwanenberg M, Hellwig E (1997) Effect of fluoride treatment on remineralization of bleached enamel. J Oral Rehab 24(4): 282-286.

7. De Oliveira R, Paes Leme AF, Giannini M (2005) Effect of a carbamide peroxide bleaching gel containing calcium or fluoride on human enamel surface microhardness. Braz Dent J 16(2):103-106.

8. Betke H, Kahler E, Reitz A, Hartmann G, Lennon A, et al. (2006) Influence of bleaching agents and desensitizing varnishes on the water content of dentin. Operative Dent 31(5): 536-542.

9. Wiegand A, Vollmer D, Foitzik M, Attin R, Attin T (2005) Efficacy of different whitening modalities on bovine enamel and dentin. Clinical Oral Invest 9(2): 91-97.

10. Burgmaier GM, Schulze IM, Attin T (2002) Fluoride uptake and development of artificial erosions in bleached and fluoridated enamel in vitro. J Oral Rehab 29(9): 799-804.

11. Bizhang M, Seemann R, Duve G, Romhild G, Altenburger JM, et al. (2006) Demineralization effects of 2 bleaching procedures on enamel surfaces with and without posttreatment fluoride application. Operative Dent 31(6): 705-709.

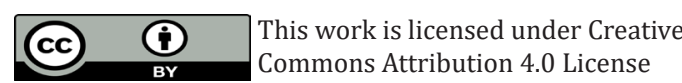

To Submit Your Article Click Here:

Submit Article

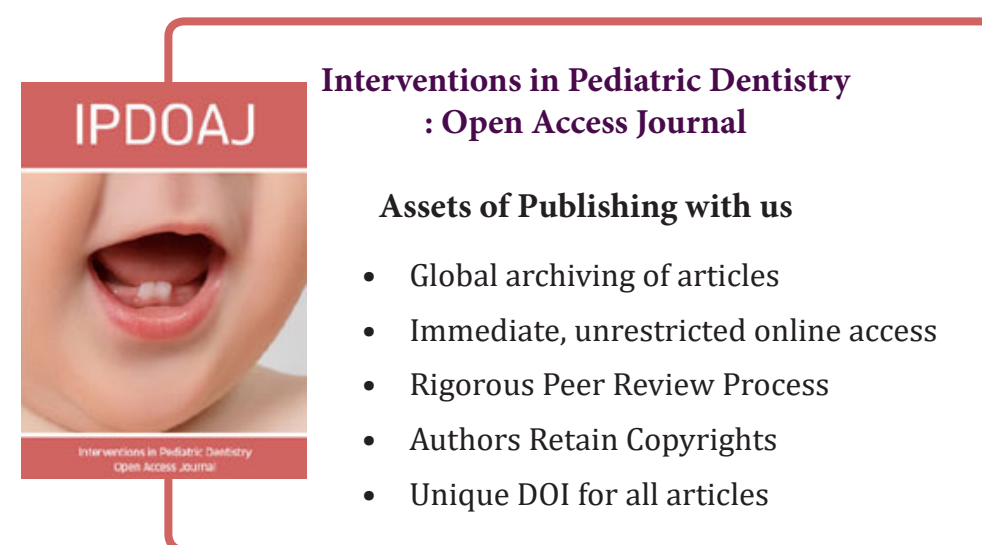

DOI: $10.32474 /$ IPDOAJ.2018.02.000136

Citation: Prashant B, Pooja B, Mahesh M, Vanitha M. Effects of Fluoridated and Non- Fluoridated Bleaching Agents on Bovine Surface Enamel. Inter Ped Dent Open Acc J 2(3)- 2018. IPDOAJ.MS.ID.000136. DOI: 10.32474/IPDOAJ.2018.02.000136. 